\title{
Formation of Highly Metastable $\beta$ Glycine by Confinement in Inkjet Printed Droplets
}

\author{
Asma B.M. Buanz and Simon Gaisford* \\ UCL School of Pharmacy, University College London, 29-39 Brunswick Square, \\ London, WC1N 1AX, UK
}

${ }^{*}$ Corresponding author.

Email: s.gaisford@ucl.ac.uk

Tel: $+44(0) 2077535863$

Fax: +44(0)207 7535942

\begin{abstract}
:
Inkjet printing was used to deposit picolitre droplets of aqueous glycine solution onto glass or aluminium substrates and it was found that the volume constraint on crystal growth resulted in formation of the highly metastable $\beta$ form. When the droplet volume increased to $0.1 \mu \mathrm{L}$ or greater a mixture of the $\alpha$ and $\beta$ forms was seen in a coffee-ring formation. When the droplet volume increased to $10 \mu \mathrm{L}$, needle-like $\beta$ crystals formed in the bulk of the ring and bipyramidal $\alpha$ crystals on the outer edge at the air-water interface. The $\beta$ form was stable under ambient conditions for at least 6 weeks. The observations suggest that glycine nucleates to, and remains stable as, the $\beta$ form when constrained in small volumes because on the nanometer-scale the $\beta$ form is thermodynamically stable. As the droplet volume increases, and constraint on crystal growth is reduced, the $\alpha$ form becomes thermodynamically stable and so phase transformation occurs, probably facilitated by a solvent-mediated mechanism. Inkjet printing picolitre droplets may offer a new route to isolation of metastable polymorphs.
\end{abstract}

\section{Key words:}

Crystal growth; Glycine; Inkjet printing; Metastable Polymorphs; Solid-state structures 


\section{Introduction}

Selection of polymorph is often a critical factor in product development, particularly in the pharmaceutical sector. Metastable forms frequently show faster dissolution and higher bioavailability than the thermodynamically stable form, but may undergo phase transformation upon storage and so lose these beneficial properties. Hence, selection of polymorph during pharmaceutical formulation involves a balance between bioavailability and stability; it follows that rational selection cannot be achieved without first knowing the range of polymorphs available and their properties, especially thermodynamic stabilities with respect to each other. Methods of screening and isolating metastable polymorphs are therefore fundamental to successful pharmaceutical product development.

Polymorph screening involves inducing crystallisation in a sample under various experimental stresses. Traditional methods force a compound to crystallise from a range of solvents (or solvent mixtures) of differing polarity, using cooling, evaporation or addition of an antisolvent to initiate nucleation. Newer methods to induce stress include the use of electric, ultrasound or shear fields and lasers to initiate nucleation. ${ }^{1-4}$ Growth of a particular polymorph may sometimes be directed by changing experimental variables, such as temperature, by adding agents such as polymers that limit diffusion rates and/or modify the surfaces of nuclei or by growing crystals on templating surfaces or other nucleation points. Although it is possible to grow particular forms using these methods, it is not always the case that the form isolated experimentally is the form that nucleated initially; Ostwald's rule of stages ${ }^{5}$ posits that when a substance crystallises from a high energy, non-equilibrium state, such as a supersaturated solution, it will arrive at the stable form having progressed through any available metastable forms. Thus it may well be the case that crystals nucleate to a metastable form before transforming to another, more thermodynamically stable, form.

More recent understanding of nucleation mechanisms suggests that the thermodynamically stable form of nanometer-scale crystals is not necessarily that observed for macroscopic crystals, because of the increasingly large surface area-tovolume ratio of small crystals ${ }^{6-7}$. Classical nucleation theory argues that formation of nuclei involves clustering of molecules with a free energy $\left(\Delta G_{\text {cryst }}\right)$ equal to the sum of the volume free energy $\left(\Delta G_{V}\right)$ and the surface free energy $\left(\Delta G_{A}\right)$. Volume free energy 
derives from intermolecular bonding and so is thermodynamically favourable while surface free energy comes from creation of interfaces between the nucleus and its surroundings and is thermodynamically unfavourable. $\Delta G_{\text {cryst }}$ is maximized at a particular nuclei radius $\left(r_{\text {crit }}\right)$. Since different polymorphs have different free energies, their corresponding $r_{\text {crit }}$ values will also differ and there is increasing evidence that if crystallization is confined in volumes approaching $r_{\text {crit }}$ that the relative thermodynamic stabilities of polymorphs may change. ${ }^{8}$

Glycine is a good example of a molecule that exhibits both polymorphism and solvent-mediated phase conversion. At atmospheric pressure it has three polymorphs; the $\gamma$ form is thermodynamically stable at room temperature but readily converts to the enantiotropically related $\alpha$ form on heating, while the highly metastable $\beta$ form is monotropically related to both other forms. ${ }^{9-11}$ The $\gamma$ form has been isolated from microemulsions containing sorbitan monooleate and polyethylene glycol dodecyl ether ${ }^{12}$, but the $\alpha$ form is often isolated from aqueous solutions because the kinetic barrier to nucleation is less than that for the stable $\gamma$ form although, interestingly, solution $\mathrm{pH}$ affects the proportion of $\gamma$ form that nucleates, because glycine ions form in acidic or basic conditions that induce linear molecular ordering that matches the structure of the $\gamma$ form ${ }^{13}$. The $\gamma$ form can also be selectively grown in preference to the $\alpha$ form from water if tailor made additives are used ${ }^{14}$. The $\beta$ form can be isolated from water/ethanol mixtures, but rapidly converts to the $\alpha$ form in solution or upon heating. Consequently, the $\alpha$ form is usually isolated from solution, even when crystallisation progresses in small volumes (down to $2 \mu \mathrm{L}$ ). Because of this phase behavior, various experimental methods have been explored to try and isolate the metastable $\beta$ form and understand the mechanisms underlying phase conversion.

Torbeev et $\mathrm{al}^{15}$ managed to grow $\beta$ glycine in solutions containing various $\alpha$ amino acids, arguing that the chirality of the amino acids made then 'perturber' molecules, directing assembly of the glycine nuclei. Poornachary et al ${ }^{16}$ showed that in microlitre droplets the $\beta$ form of glycine nucleated at the contact line between air and solution interface while the $\alpha$ form nucleated and grew in the bulk droplet. With time, the $\beta$ form converted to the $\alpha$ form via a solvent mediated mechanism. By reducing the size of the droplets using nano spray drying, Yang and Myerson ${ }^{17}$ successfully isolated metastable forms of glycine; generally concomitant nucleation of two 
polymorphs ( $\alpha$ and $\beta$ ) was seen, although raising the spraying temperature and/or concentration of solute or lowering solution $\mathrm{pH}$ increased the proportion of the $\beta$ form. Confining the space for crystallisation further, self-assembled monolayers (SAMs) have been used to modify the surface chemistry of metallic islands (typically of gold and ca. $1 \mu \mathrm{m}$ in diameter) on which crystal growth occurs. This method has produced the $\beta$ form of glycine ${ }^{17-19}$, the proportion isolated being dependent on the size of the island, surface chemistry, solvent composition and rate of cooling.

The development of inkjet printing (IJP) technology means it is possible to deposit individual droplets of picolitre volume (typically between 7-200 pL) and so the technology offers significant, but hitherto relatively unexplored, potential for crystallising materials under conditions of confined volume ${ }^{20-21}$. Sanandaji et al $^{22}$ report using inkjet printing to study crystallization of polycaprolactone in $\mathrm{pL}$ droplets. The spatial confinement caused crystallization to metastable phases believed to be precursors to stable crystalline structures of the polymer. An additional benefit of inkjet printing technology is the ability to deposit droplets onto various substrates. For instance, paracetamol, theophylline and caffeine have been shown to form crystals when printed onto a non-porous substrate, but to form solids that are semi-crystalline when printed onto a porous substrate ${ }^{23}$, while caffeine has been reported to crystallise to needles ${ }^{24}$ and prednisolone found to crystallise to two forms when printed on a hydrophobic substrate ${ }^{20}$.

Here, the specific focus of this work was to investigate the crystallisation of glycine under confinement in $\mathrm{pL}$ droplets produced by inkjet printing onto various substrates, with a view to understanding whether the metastable $\beta$ form could be isolated and determining how droplet volume influences polymorphic transformations to the $\alpha$ form.

\section{Experimental section}

A Jetlab $^{\text {TM }}$ 4XL-A research printing platform (MicroFab technologies Ltd, USA) was used to print droplets onto different substrates. The piezoelectric system allows dispensing of individual as well as multiple droplets. Glycine solution $(0.5 \mathrm{M})$ in HPLC-grade water was filtered through a $0.45 \mu \mathrm{m}$ Nalgene ${ }^{\mathrm{TM}}$ PTFE filter (Thermo Scientific, USA) and dispensed from either $40 \mu \mathrm{m}$ nozzle (MJ-AT-01) dispensing devices at $300 \mathrm{~Hz}$ using a driving voltage of $20 \mathrm{~V}$ and a pressure of $-0.2 \mathrm{psi}$ above 
the printing solution. Various numbers ( 1 to 3000 ) of droplets were dispensed onto glass slides, aluminium foil or Micromesh ${ }^{\mathrm{TM}}$ powder X-ray diffraction (PXRD) mounts. A horizontally mounted camera allowed the observation of printed droplets and calculation of their properties with the dedicated droplet analysis software while a downward-looking camera was used to inspect the printed material.

$10 \mu \mathrm{L}$ droplets of filtered solution of $0.5 \mathrm{M}$ glycine in water were placed on glass or aluminium foil using a $20 \mu \mathrm{L}$ Gilson pipette and were allowed to evaporate at room temperature and humidity until complete dryness.

Raman spectra were collected using Renishaw inVia Raman microscope (Leica DM LM, Leica Microsystems, Wetzlar $\mathrm{GmbH}$ ) equipped with a visible laser operated at $514.5 \mathrm{~nm}$ and a Philips camera. The spectra were collected between 100 and 3200 $\mathrm{cm}^{-1}$ every 10 seconds, with 4 accumulations using a long working distance objective lens (50x). Data capture was performed using Renishaw WiRE software (version 2.0, Renishaw plc, UK).

An Oxford Diffraction Xcalibur NovaT X-ray diffractometer (Cu Ka radiation, $\lambda=$ $1.5418 \AA$ ) operated at room temperature was used to collect diffraction data from samples crystallised on the PXRD Micromesh ${ }^{\mathrm{TM}}$. The sample was mounted using transmission geometry, processed, and scaled using CrysAlis ${ }^{\mathrm{PRO}}$ software (Rigaku Oxford Diffraction). The sample was mounted perpendicularly to the Phi axis and rotated over $360^{\circ}$ at $0.25^{\circ} / \mathrm{s}$.

\section{Results and discussion}

Each droplet produced by the inkjet printer used here was of ca. $100 \mathrm{pL}$ volume, so to deposit solutions of various volumes on the substrate it was necessary to print multiple droplets in the same location and allow them to coalesce. In this way, the printer was used to deposit droplets ranging in volume from $100 \mathrm{pL}$ to $0.3 \mu \mathrm{L}$ ( 1 to 3,000 droplets) on either glass or aluminium. Following printing, solvent evaporation was allowed to occur at room temperature. It is apparent from the light microscopy images of the resulting crystals that the droplets spread more on glass than on aluminium and that a clear coffee-ring effect is observed in both cases (Figure 1, which shows droplets of $0.3 \mu \mathrm{L}$ but similar patterns were observed in printed droplets of all volumes, SI Figure S1). This process is shown clearly during the process of 
drying (SI video 1 and 2). Raman spectra were collected from random crystals (Figure 2). Absorbance bands characteristic to each polymorph were used for form identification $\left(\alpha 2973,1411\right.$ and $1325 \mathrm{~cm}^{-1} ; \beta 2954,1409$ and $1321 \mathrm{~cm}^{-1} ; \gamma 2964$, 1398 and $1324 \mathrm{~cm}^{-1}$. The bands correspond to $\mathrm{CH}_{2}$ symmetric stretching, $\mathrm{CH}_{2}$ twisting and $\mathrm{CO}_{2}$ symmetric stretching respectively ${ }^{25}$ ). It can be seen that the $\beta$ form is present in all samples; when the droplet size is small the sample is all $\beta$ and as the droplet volume increases there is a mixture of the $\alpha$ and $\beta$ forms. Our observation of the $\beta$ form correlates with those studies using metallic islands functionalised with SAMs ${ }^{17-19}$, although in our work it is notable that the beta form was obtained without the need for surface functionalisation.

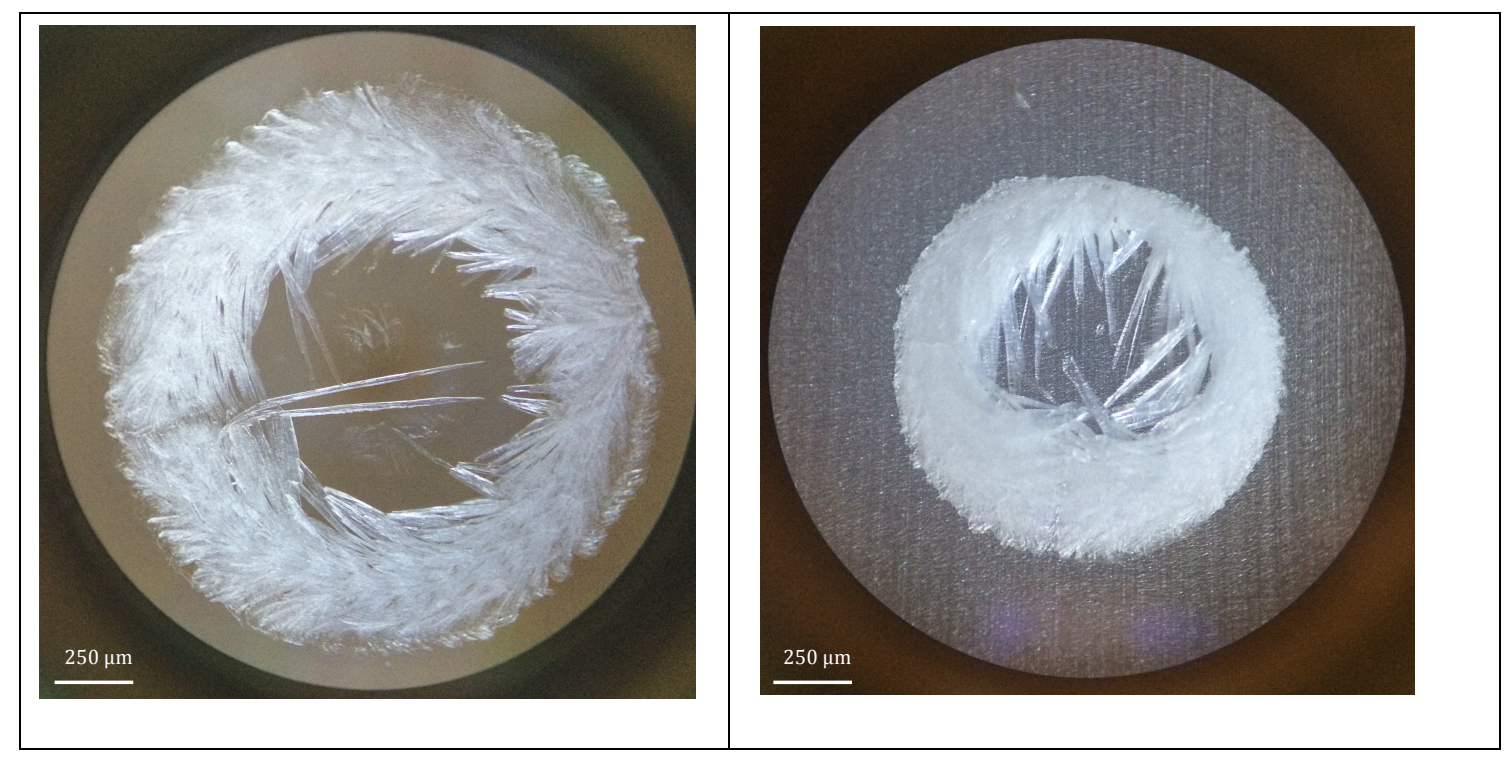

Figure 1. Light microscopy images of glycine crystals formed in printed droplets $(0.3$ $\mu \mathrm{L}$ ) on glass (left) and aluminium foil (right), showing clear coffee ring formation 

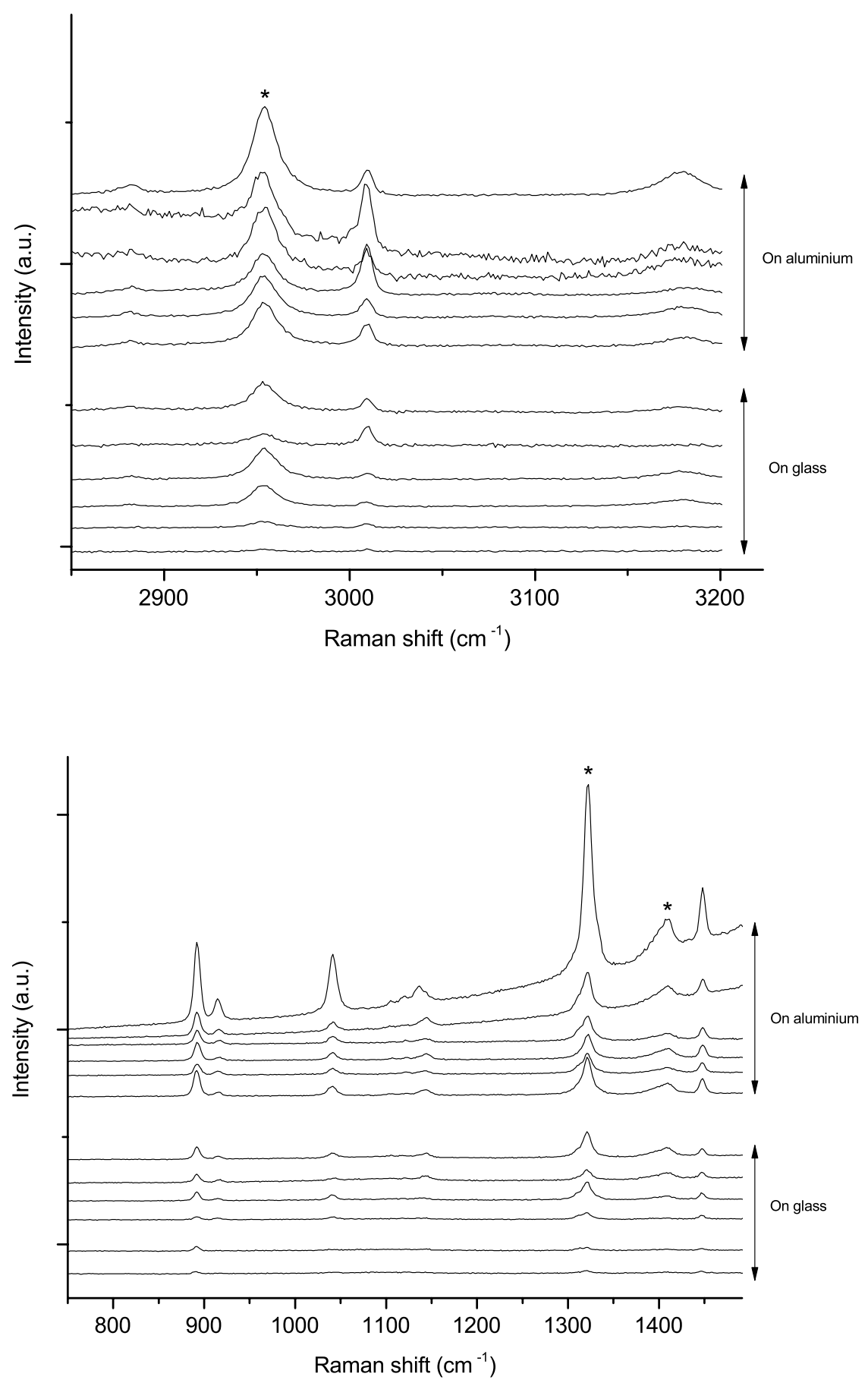

Figure 2. Raman spectra of randomly selected glycine crystals produced by inkjet printing droplets $(1,10,200,1,000,2,000$ and 3,000), printed on either glass or aluminium, showing predomination of the $\beta$-form with characteristic $\left(^{*}\right) \mathrm{CH}_{2}$ symmetric stretching peaks at 2953 (top), $\mathrm{CH}_{2}$ twisting at 1320 and $\mathrm{CO}_{2}$ stretch at $1408 \mathrm{~cm}^{-1}$ (bottom). 
Crystal growth in larger (up to $10 \mu \mathrm{L}$ ) droplets, prepared with a micro-pipette, was also examined. Here, again, a clear coffee-ring effect is seen, but unlike in the case of the printed droplets two crystal habits can be observed near the edge; needle-like and bipyramidal (Figure 3). Raman spectra were collected from crystals of each habit. The spectra show that the needle crystals were the $\beta$ form, while the bipyramidal crystals were of the $\alpha$ form (Figure 4); these morphologies are also typical of the two polymorphs ${ }^{11}$. This is consistent with the findings of Poornachary et $\mathrm{al}^{16}$, who reported the conversion of $\beta$ crystals to $\alpha$ crystals with similar morphologies in droplets between 2 and $50 \mu \mathrm{L}$. However, their study utilised much higher concentrations that used in our work $(2.5 \mathrm{M}$ compared with $0.5 \mathrm{M})$. They also reported formation of the $\alpha$ form within the bulk of the droplet but in our study (for example in Figures 1 and 3) there was no evidence of $\alpha$ formation within the bulk of the droplet, an event that would have resulted in crystals in the centre of the coffee ring. The lower concentration in our study could mean that as the solute migrated to the edge with the solvent, less remained in the bulk, thus reducing the chances of nucleation and/or transformation to the $\alpha$ form in the bulk of the droplet.

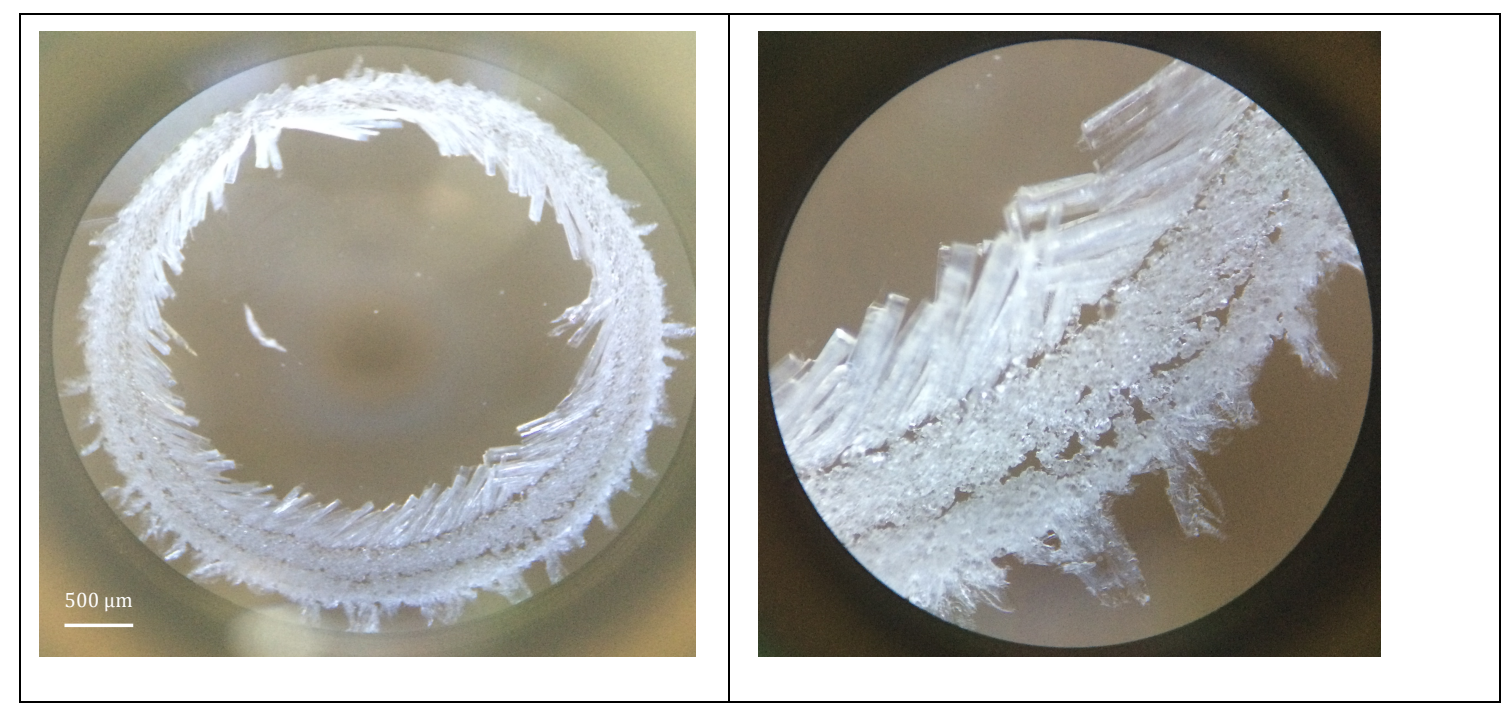

Figure 3. Light microscopy images of glycine crystals formed in larger (10 $\mu \mathrm{L})$ droplets on glass, showing coffee ring formation as well as two crystal habits. 


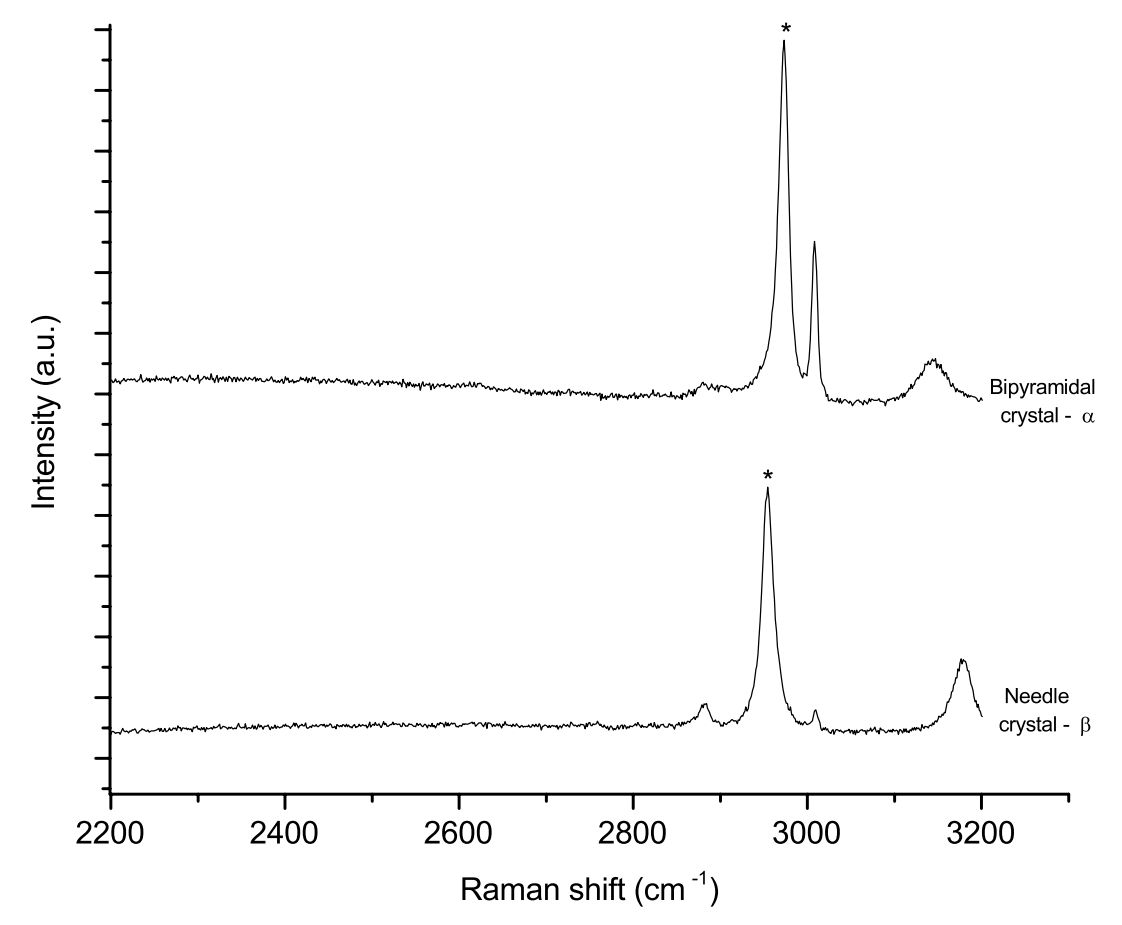

Figure 4. Raman spectra for bipyramidal and needle-like crystals resulting from $10 \mu \mathrm{L}$ droplets, showing the bipyramidal crystals are of the $\alpha$ form (characteristic $\mathrm{CH}_{2}$ stretch at $2973 \mathrm{~cm}^{-1}$ ) and needle-like crystals are $\beta$ (characteristic $\mathrm{CH}_{2}$ stretch at $2954 \mathrm{~cm}^{-1}$ )

One experimental issue with printing droplets is that only a fraction of the crystals produced can be analysed with Raman microscopy. Thus, while only the $\beta$ form was seen, the possibility that some crystals of the $\alpha$ forms were present could not be discounted. Therefore, an innovative method of analyzing the printed sample in its entirety was essential. This was achieved by printing droplets of solution directly onto MicroMesh ${ }^{\mathrm{TM}}$ PXRD sample holders (which have a mesh size of $10 \mu \mathrm{m}$ ), which are designed to retrieve small crystals from solutions. Images of 8 droplets (100 pL each) printed onto the mesh and the crystals formed after solvent evaporation are shown in Figure 5. SEM images of the crystals clearly show growth is confined to the space with each grid, Figure 6 (left). When 50 drops are printed onto the mesh, the droplets coalesce and crystal growth proceeds above the mesh, resulting in less confinement, Figure 6 (right). The corresponding PXRD data for the 8 printed drops show that only the $\beta$ form is present (Figure 7 - similar results were seen for larger droplets (up to 20 $\mathrm{nL}$, or 200 printed drops, SI Figures S2 and S3). 


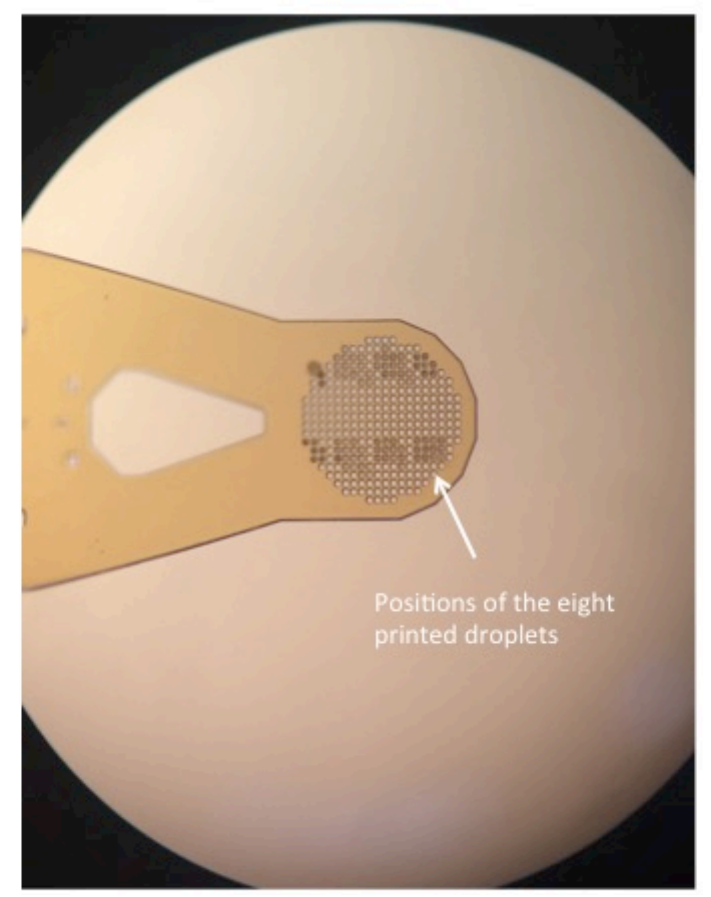

Figure 5. Images of glycine crystals from eight droplets (100 pL each) printed onto the PXRD Micromesh holder.
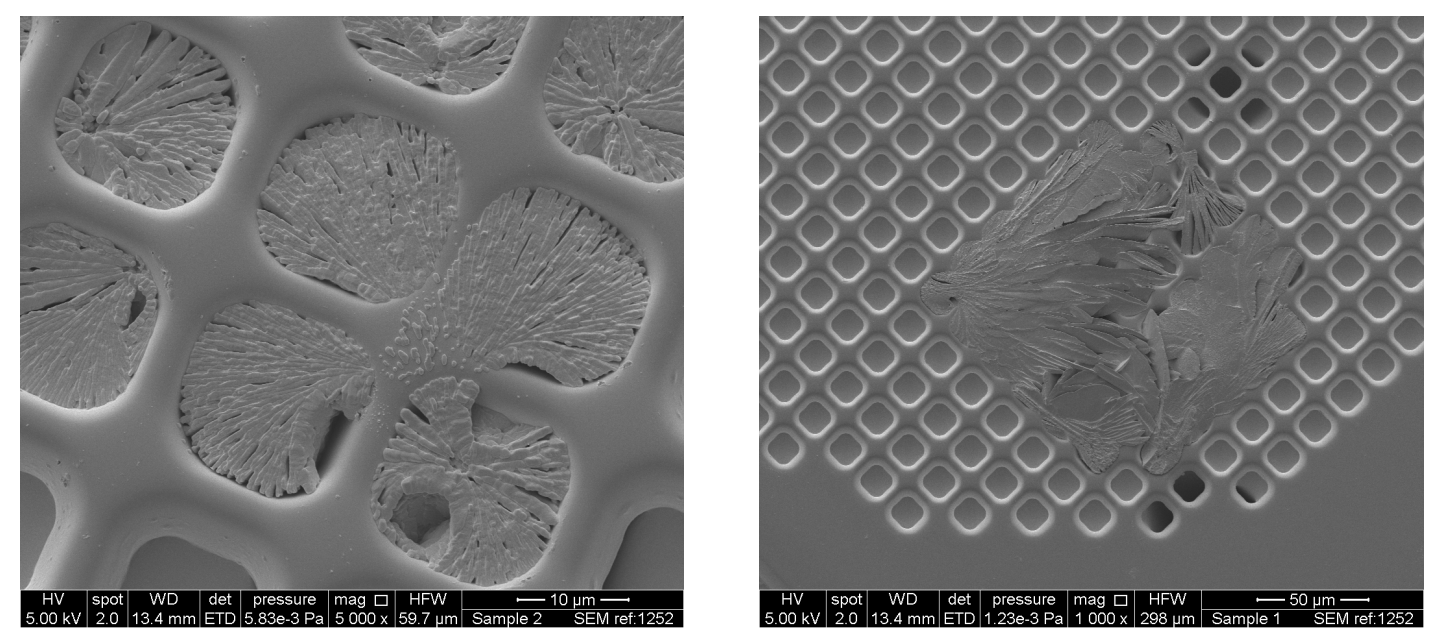

Figure 6. SEM images of the crystals produced from single droplets $(100 \mathrm{pL})$ printed onto the PXRD Micromesh holder (left), showing confinement of crystal growth within the mesh, and 50 droplets ( $5 \mathrm{~nL}$, right) showing crystal growth above the mesh. 


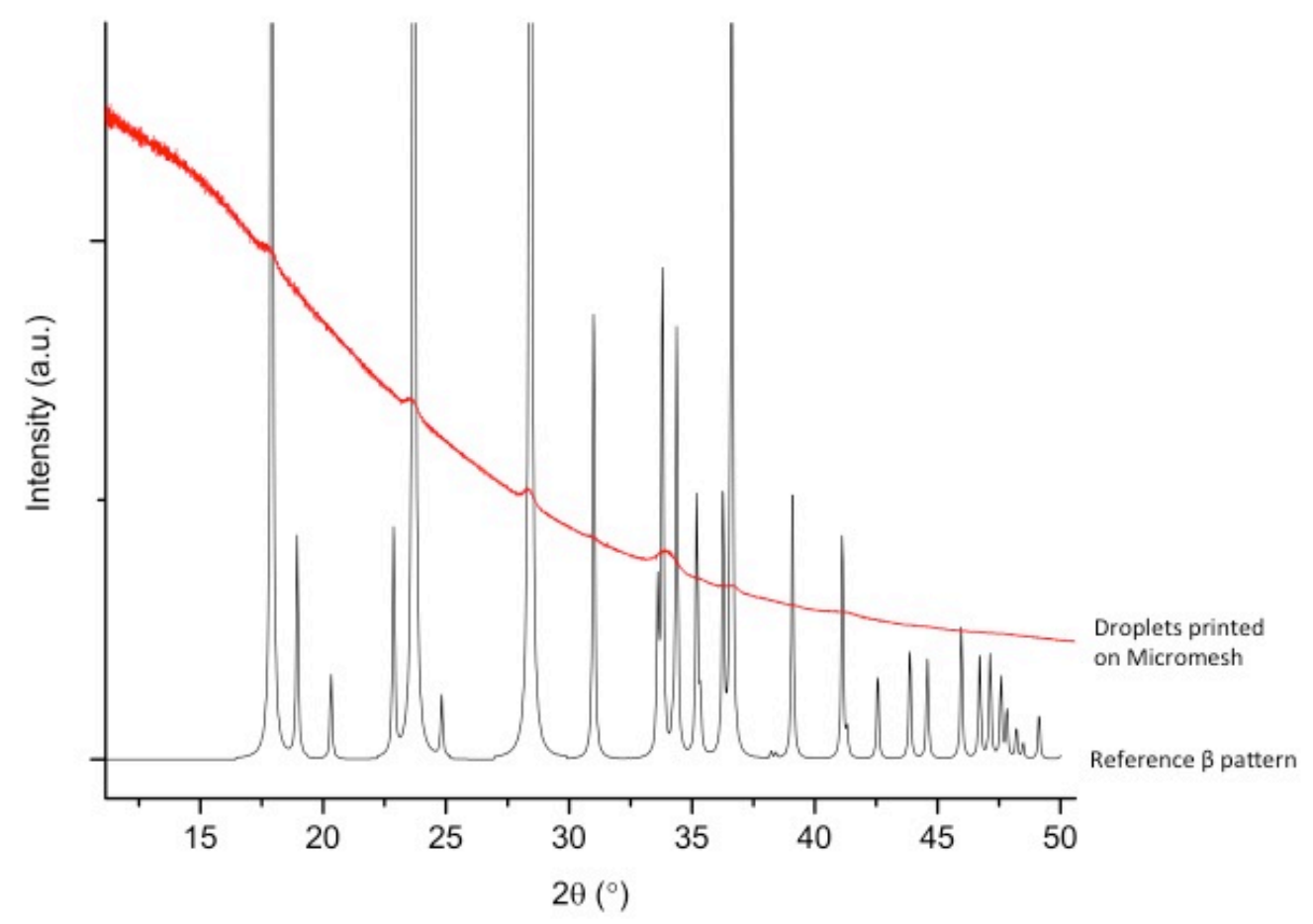

Figure 7. PXRD diffraction pattern from glycine crystals resulting from droplets printed on the Micromesh and the reference pattern for the $\beta$ form.

These findings allow a mechanism to be proposed that results in formation of the metastable $\beta$ form. For small volumes (100 pL), nucleation is confined to the extent that growth occurs over a length similar to $r_{\text {crit }}$. Under these conditions, the $\beta$ form is thermodynamically stable, which is why it is isolated. For larger droplets, coffee-ring formation is interpreted to be an indication that capillary flow is faster than the evaporation rate ${ }^{26-27}$. In other words, rapid transportation of solvent to the edge of the droplet results in concomitant movement of glycine molecules to the edge of the droplet, where evaporation occurs. This creates a high degree of supersaturation at the edge of the droplet, favouring nucleation of the $\beta$ form, even though it is thermodynamically metastable on these length scales. Following nucleation, solventmediated conversion to the $\alpha$ form occurs if solvent is present for a sufficient period of time, leading to the observation of macroscopic $\alpha$ crystals in larger droplets. This is shown by Figure 3 where, it can be noticed in the $10 \mu \mathrm{L}$ droplets that the coffeering corona is divided into two or three rings, with $(\beta)$ needles crystallised on the inner surfaces and $(\alpha)$ bipyramidal crystals formed near the external air-water interface. 
These mechanisms suggest that the $\beta$ crystals should be stable with time for $\mathrm{pL}$ droplets, but may convert to $\alpha$ in larger droplets. All inkjet printed samples, either on aluminium or glass, were stored for a period of 6 weeks at room temperature and humidity and subsequently analysed to determine their polymorphic form. It is clear from the Raman spectra given in Figure 7 that the $\beta$ form remains to an extent in all samples, but that as the volume of the droplet increases, an increasing amount of the $\alpha$ form is seen. Similar results were observed for samples printed on the PXRD mesh (SI Figure S4), thus confirming the mechanisms.

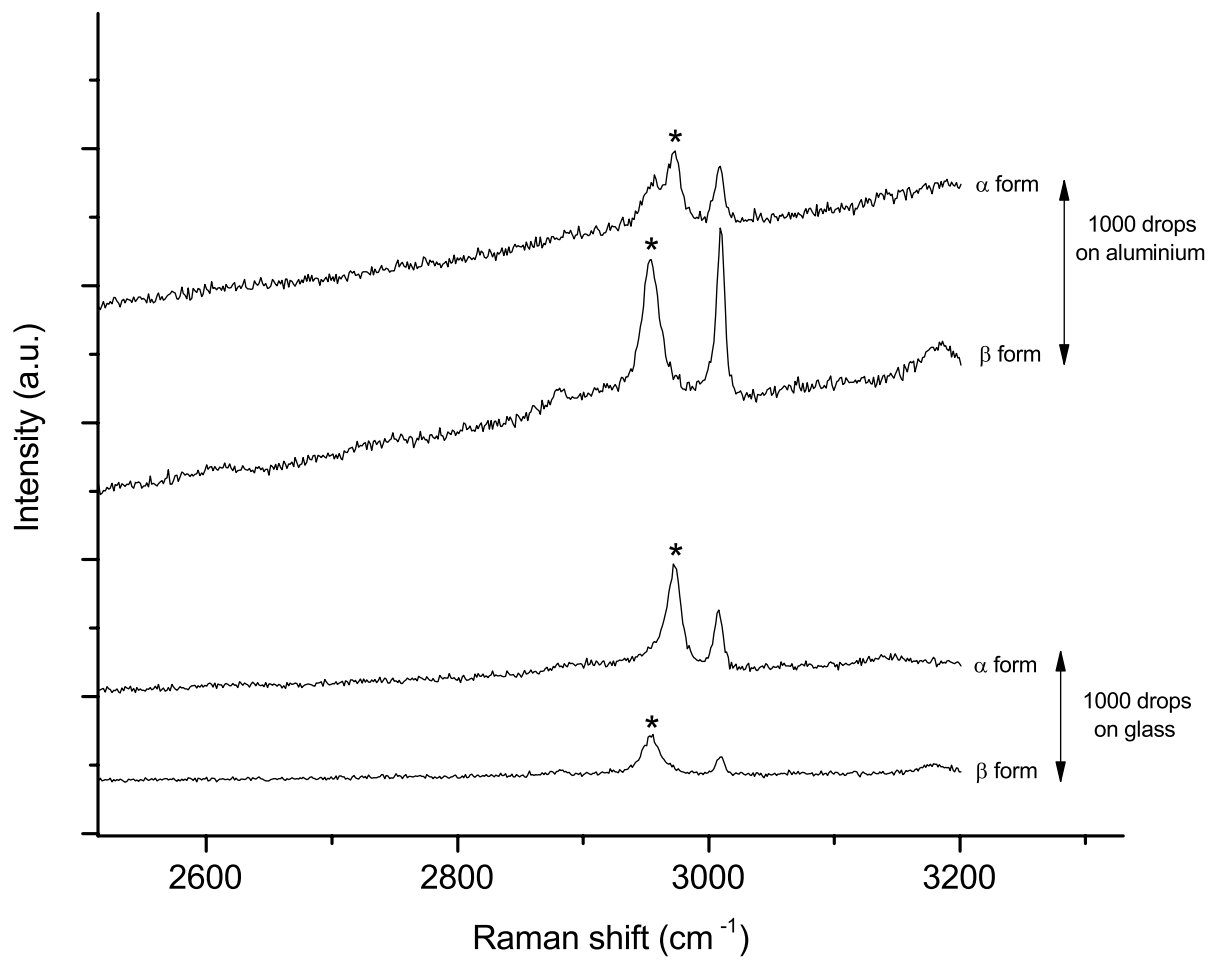

Figure 7. Raman spectra of crystals from inkjet printed droplets on glass and aluminium after storage for 6 weeks, showing retention of the $\beta$ form but some conversion to the $\alpha$ form

No evidence of the substrate surface on directing nucleation to a particular form was observed in our study. Seyedhosseini et $\mathrm{al}^{28}$ reported the formation of the $\beta$ form in $50 \mu \mathrm{L}$ droplets on a platinum substrate but they had to reduce the solution concentration to achieve that. In our study, at the same concentration and on the same substrate, $\mu \mathrm{L}$ droplets produced a mixture of $\beta$ and $\alpha$ forms, while printed $(<0.1$ $\mu L$ ) droplets produced the $\beta$ form. This suggests that it is the size of the droplet that 
is controlling the outcome of crystallization through the effect on the evaporation rate or by constraining nuclei growth, which is consistent with previous reports of the effect of the evaporation rate in obtaining the $\beta$ form and it has also been suggested for other molecules ${ }^{11,29}$.

Interestingly, a recent study showed that $\beta$ glycine could be obtained from water, water-ethanol and/or water-acetone droplets using a vibrating orifice aerosol generator $(\mathrm{VOAG})^{30}$. The authors obtained spherical particles from droplets of $\sim 46$ $\mu \mathrm{m}$ and XRD showed exclusively the $\beta$ form. Since these droplets dry in air the authors argue that the unique drying environment, in which only an air-water interface is present, directs crystallization to the $\beta$ form. The morphology of the crystals obtained did not, however, match the characteristic needles of the $\beta$ form, but were rather of plate-like morphology. Further, while their crystals were stable for at least a month under desiccated air, under slight humidity $(30 \%)$ conversion to the $\alpha$ form was seen in $24-48 h$.

\section{Conclusion}

Formation of the unstable $\beta$ form of glycine from water was achieved from inkjet printed droplets on a variety of surfaces. It was possible to print a single, $100 \mathrm{pL}$, droplet and, by printing multiple droplets in the same area, to print droplets up to 0.3 $\mu \mathrm{L}$. In all printed droplets, glycine was seen to crystallise to the highly metastable $\beta$ form. When the droplet volume was increased to greater than $0.1 \mu \mathrm{L}$ by using a micropipette, crystals of both $\alpha$ and $\beta$ were produced. It is hypothesized that in $\mathrm{pL}$ droplets, growth of nuclei is constrained to such an extent that the $\beta$ form is the thermodynamically stable form. In larger droplets, rapid evaporation of water from the printed droplets enables glycine to nucleate to the (now metastable) $\beta$ form, but that solvent-mediated form transformation to the $\alpha$ form is inhibited. The $\beta$ crystals from the printed droplets were stable for 6 weeks at room temperature and humidity while conversion to the $\alpha$ form was seen upon storage for crystals produced from $\mu \mathrm{L}$ droplets. Substrate surfaces were not seen to influence the form which crystallised. The precision of the printing system allowed printing onto PXRD meshes and so easy diffraction analysis of the crystal form produced upon drying that was consistent with the characterization of single crystals by Raman spectroscopy and its ability to print $\mathrm{pL}$ droplets should enable exploration and isolation of polymorphs that are thermodynamically metastable on a macroscopic scale. 


\section{Acknowledgement}

The work was supported by ESPRC (grant reference EP/K039229_1). The authors thank Profs Sarah (Sally) Price, Derek Tocher and Alastair Florence for critical review and comments. 
Supplementary information:

Table of contents

1. Materials

2. Imaging

3. Light microscopy images of glycine crystals formed in $10 \mu \mathrm{L}$ drops on aluminum ( $a$ and b), and printed droplets on glass (c, e and g) and aluminum foil (d, f, and h) made of 2000, 1000 and one drops respectively) (Figure S1).

4. Images of 200 droplets of solution printed onto a PVC-coated and uncoated MicroMesh holder ( $a$ and $b$ ) and close-up image of the crystals produced after evaporation (c and d) (Figure S2).

5. XRPD diffraction patterns for crystals printed on the PVC-coated and uncoated MicroMesh holder and the beta form of glycine (Figure S3).

6. PXRD data for printed glycine after 6 weeks in comparison to the beta form (Figure S4).

7. Calculated PXRD patterns for alpha (CSD Ref GLYCIN02) and beta (CSD Ref GLYCIN25) (Figure S5).

8. Video showing the drying of printed droplets on glass (Video 1)

9. Video showing the drying of printed droplets on aluminium (Video 2)

Materials: Glycine (99\%) was purchased from (Alfa Aesar, UK) and used as received. HPLC water was purchased from Sigma Aldrich (UK). Glass slides (Thermo scientific, Germany) were cleaned by sonication in $2 \% \mathrm{v} / \mathrm{v}$ cleaning solution (Micro-90® concentrated cleaning solution, Sigma Aldrich, USA) for 15-30 minutes, rinsed and sonicated with distilled water for 15-30 minutes then dried in a fan oven at $70^{\circ} \mathrm{C}$. Poly (vinyl chloride) (PVC, low molecular weight) was purchased from sigma Aldrich (USA). Powder X-ray diffraction mount (Micromesh ${ }^{\mathrm{TM}}$, MiTeGen LLC, USA;

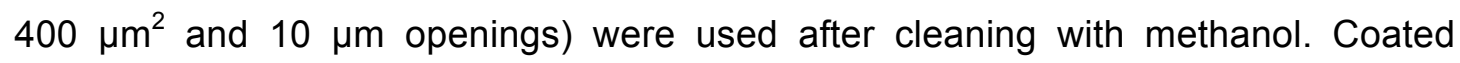
mounts were prepared by using $2 \% \mathrm{w} / \mathrm{v}$ PVC solution in tetrahydrofurane and dried overnight before use.

Imaging: Images of crystals were taken by either Leica Galen III microscope (Leica Microsystems, Wetzlar $\mathrm{GmbH}$ ) connected to the camera of an iPhone 5s (Apple Inc, USA) by using HookUpz Universal adaptor (Carson Optical, USA), Leica DM LM, Leica Microsystems, Wetzlar $\mathrm{GmbH}$ ) connected to a Philips camera. 

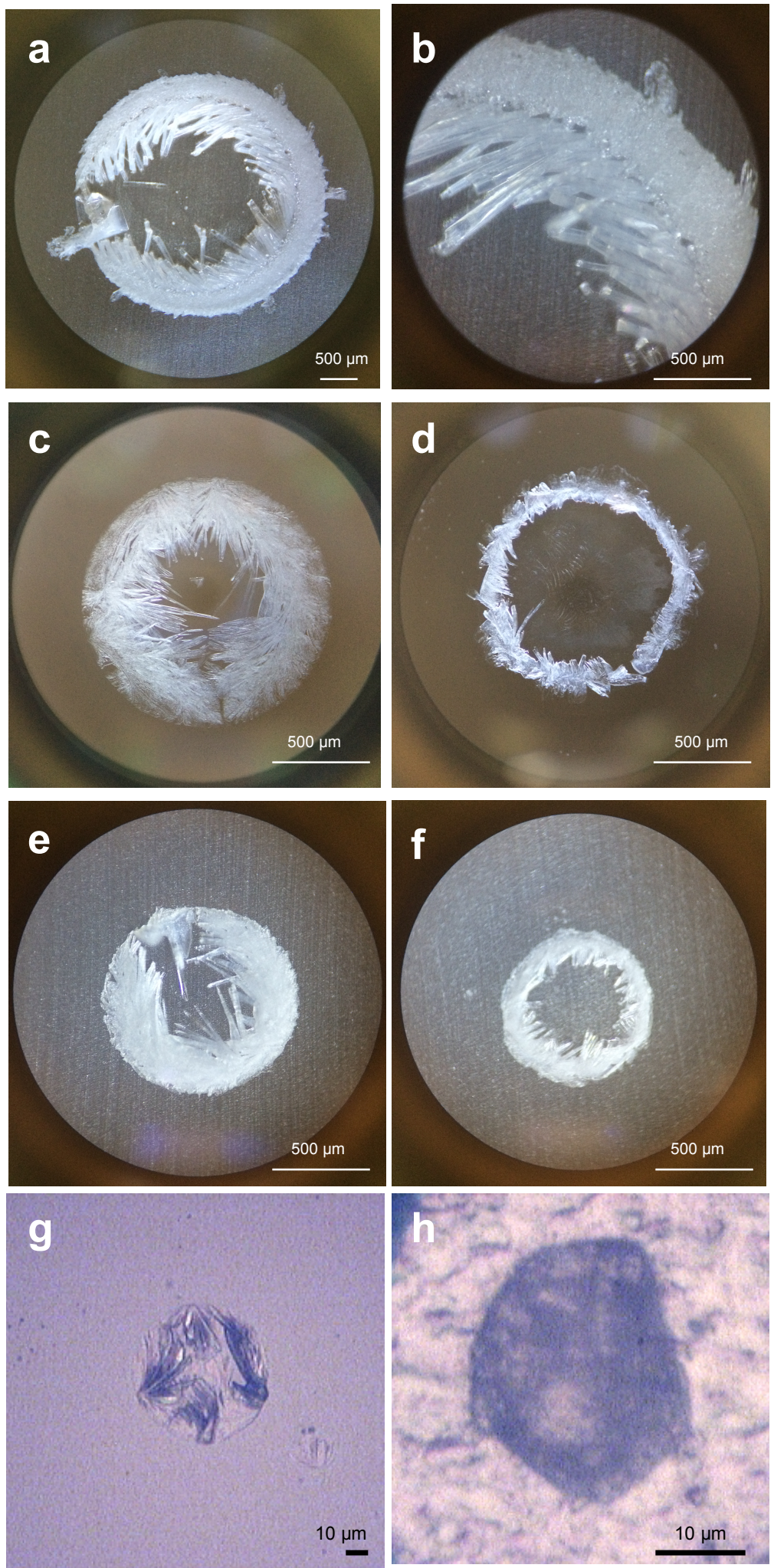

Figure S1. Light microscopy images of glycine crystals formed in $10 \mu \mathrm{L}$ drops on aluminum ( $a$ and $b$ ), and printed droplets on glass (c, e and g) and aluminum foil ( $d$, $f$, and $h$ ) made of 2000,1000 and one drops respectively. 

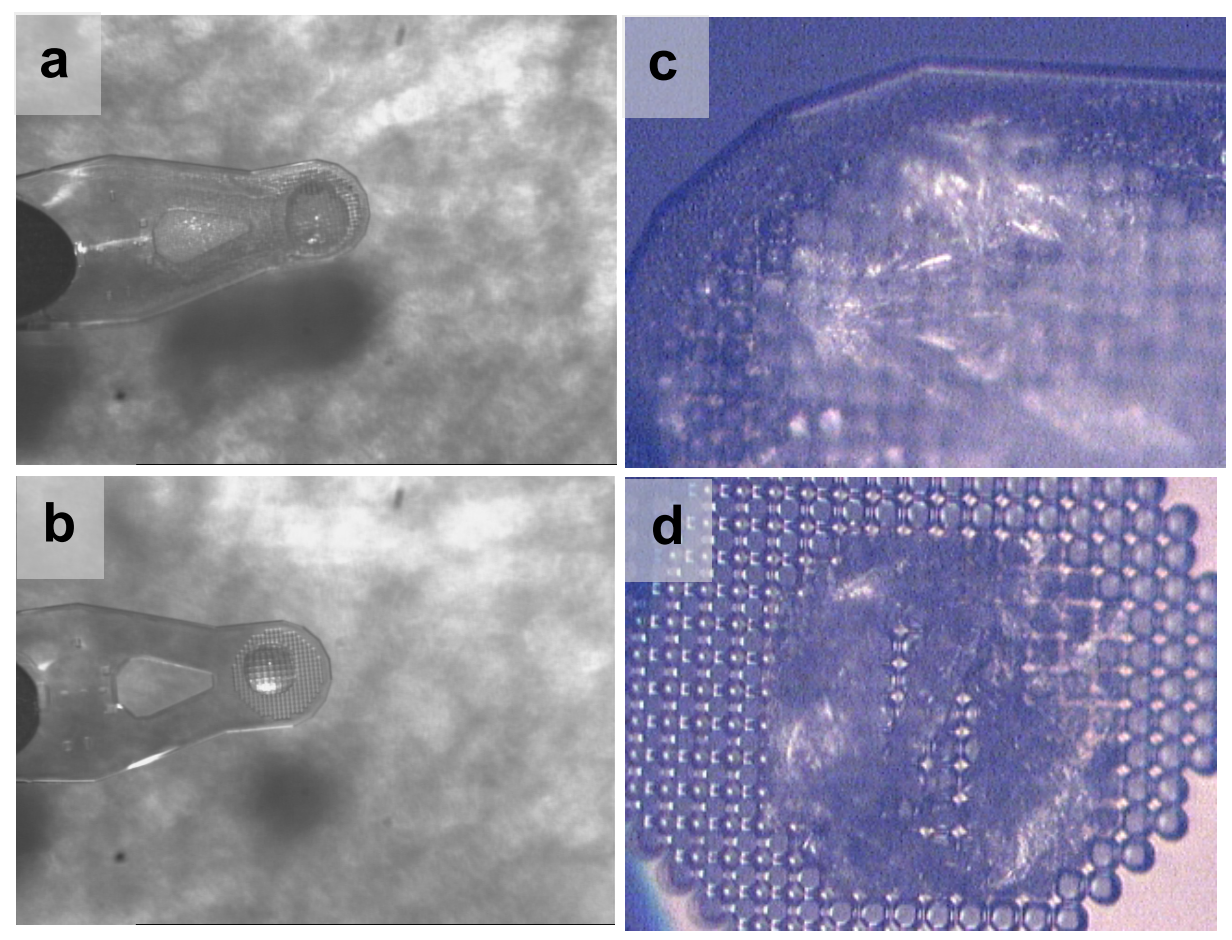

Figure S2. Images of 200 droplets of solution printed onto a PVC-coated and uncoated MicroMesh holder ( $a$ and $b$ ) and close-up image of the crystals produced after evaporation (c and d). 


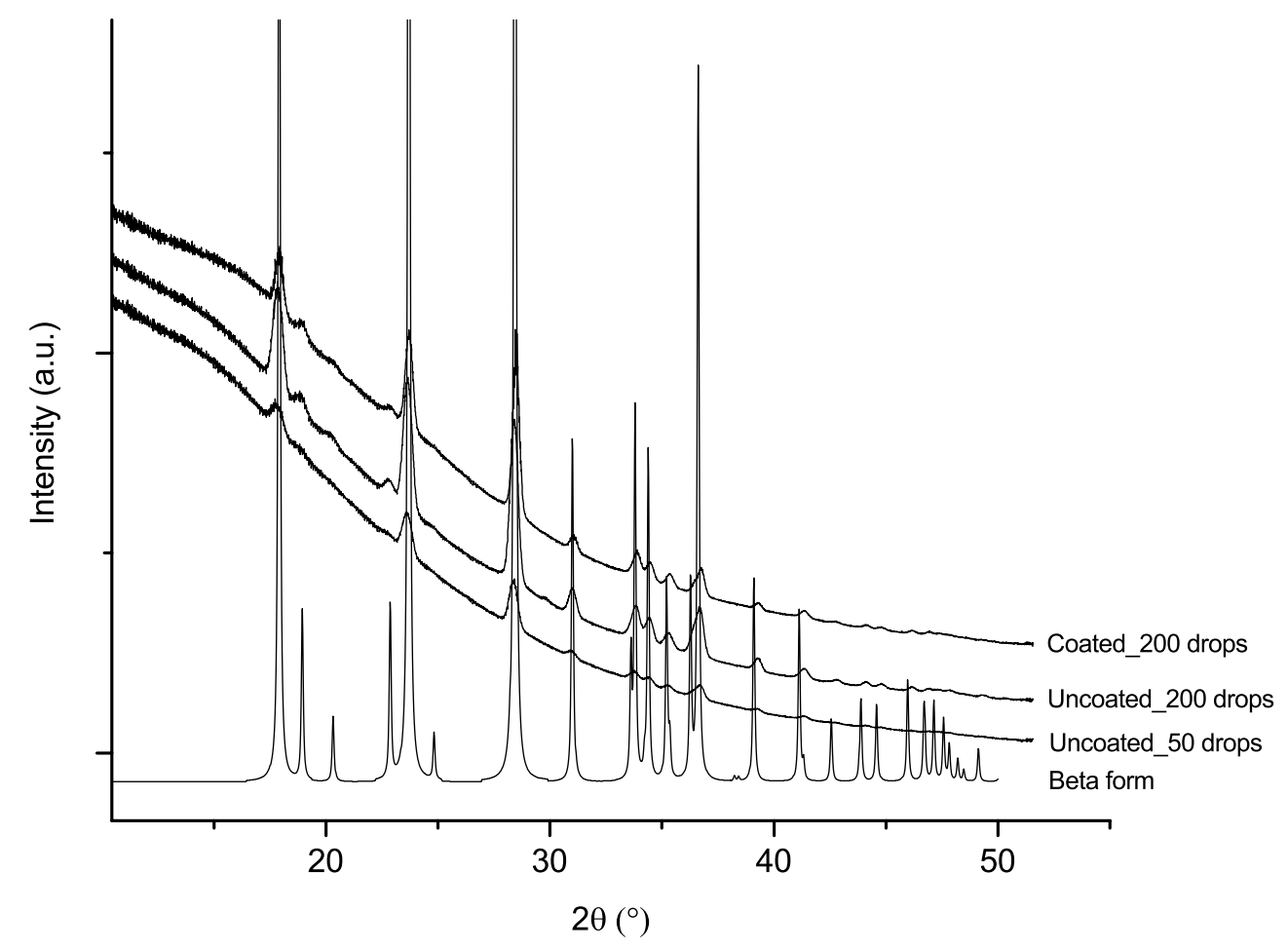

Figure S3. XRPD diffraction patterns for crystals printed on the PVC-coated and uncoated MicroMesh holder and the beta form of glycine 


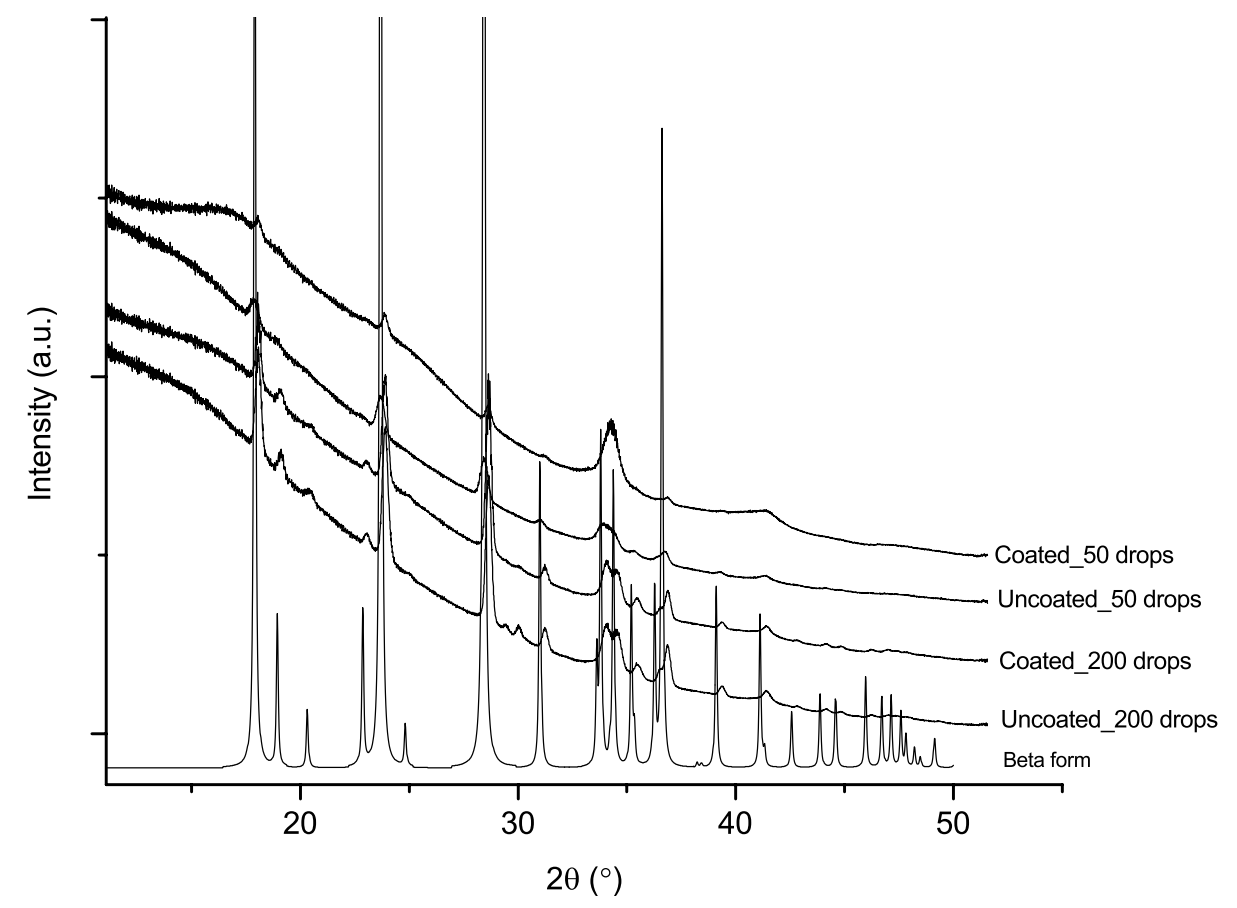

Figure S4. PXRD data for printed glycine after 6 weeks in comparison to the beta form 


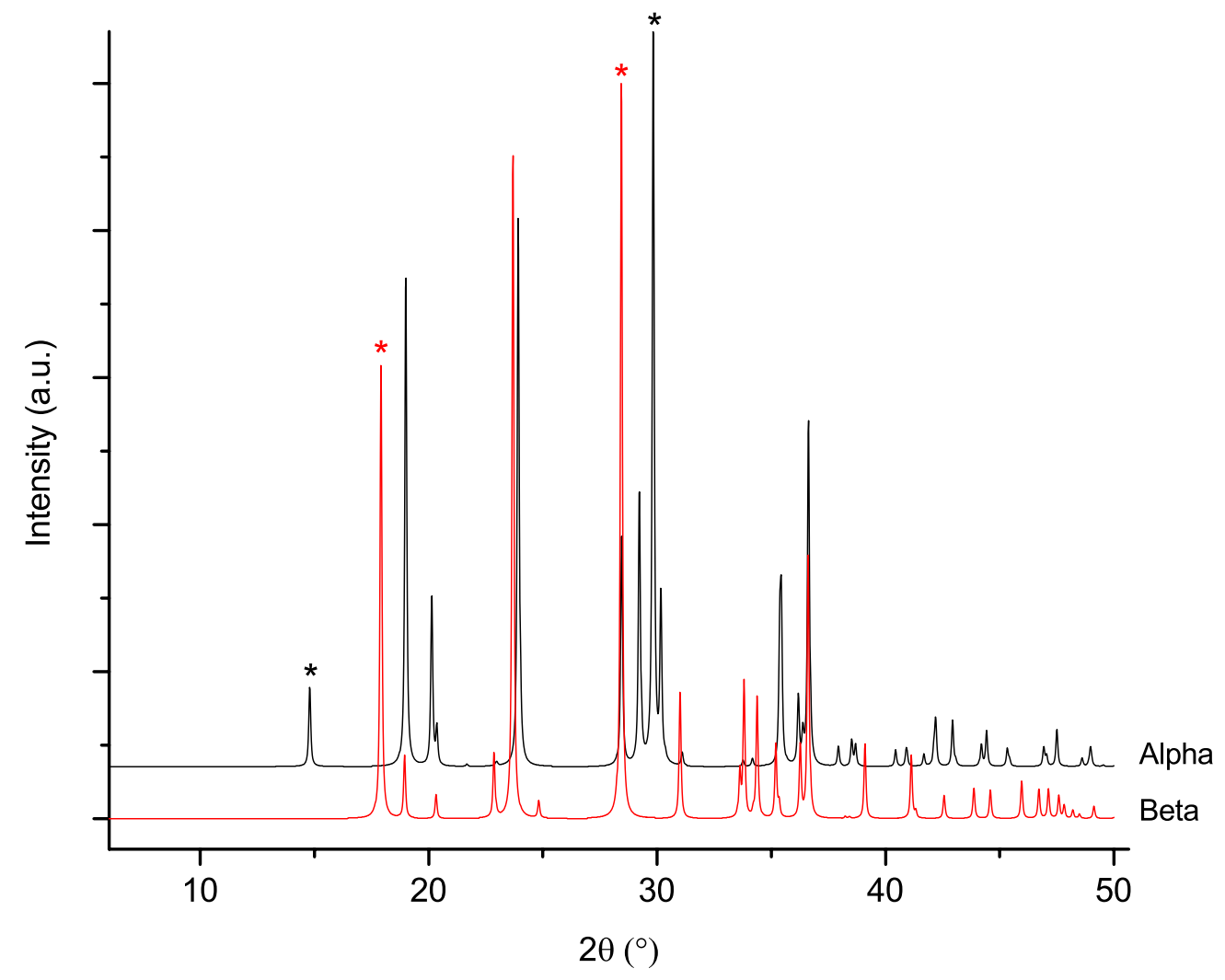

Figure S5. Calculated PXRD patterns for alpha (CSD Ref GLYCIN02) and beta (CSD Ref GLYCIN25) 
References:

(1) Zamanipoor, M.H.; R.L. Mancera, R.L. Trends Food Sci. Technol. 2014, 38, 4759.

(2) Forsyth, C.; Mulheran, P.A.; Forsyth, C.; Haw, M.D.; Burns, I.S.; Sefcik, J. Cryst. Growth Des. 2015, 15, 94-102.

(3) Koizumi, H.; Uda, S.; Fujiwara, K.; Tachibana, M.; Kojima, K.; Nozawa, J. J. Appl. Crystallogr. 2015, 48, 1507-1513.

(4) Javid, N.; Kendall, T.; Burns, I.S.; Sefcik, J. Cryst. Growth Des. 2016, 16, 41964202

(5) Ostwald, W. Z. Phys. Chem. 1897, 22, 289-330

(6) Belenguer, A.M.; Lampronti, G.I.; Cruz-Cabeza, A.J.; Hunter, C.A.; Sanders, J.K.M. Chem. Sci. 2016, 7, 6617-6627.

(7) Jiang, Q.; Ward, M.D. Chem. Soc. Rev. 2014, 43, 2066-2079.

(8) Ward, M.D. Israel J. Chem. In press. DOI: 10.1002/ijch.201600071.

(9) litaka, Y. Acta Crystallogr. 1961, 14, 1-10.

(10) Boldyreva, E.V.; Drebushchak, V.A.; Drebushchak, T.N.; Paukov, I.E.;

Kovalevskava, Y.A.; Shutova, E.S.; J. Therm. Anal. Cal. 2003, 73, 409-418.

(11) Lee, A.Y.; Lee, I.S.; Dette, S.S.; Boerner, J.; Myerson, A.S. JACS 2005, 127, 43, 14982-14983.

(12) Chen, C.; Cook, O.; Nicholson, C.E.; Cooper, S.J.; Cryst. Growth Des. 2011, 11, 2228-2237

(13) Han, G.; Thirunahari, S.; Chow, P.S.; Tan, R.B.H. CrystEngComm, 2013, 15 , 1218-1224.

(14) Dowling, R.; Davey, R.J.; Curtis, R.A.; Han, G.; Poornachary, S.K.; Shan Chow, P.; Tan, R.B.H. ChemComm, 2010, 46, 5924-5926.

(15) Torbeev, V.Y.; Shavit, E.; Weissbuch, I.; Leiserowitz, L.; Lahav, M. Cryst. Growth Des. 2005, 5, 2190-2196

(16) Poornachary, S.K.; Parambil, J.V.; Chow, P.S.; Tan, R.B.H.; Heng, J.Y.Y. Cryst. Growth Des. 2013, 14, 1180-1186.

(17) Yang, X.; Myerson, A.S. CrystEngComm 2015, 17, 723-728

(18) Kim, K.; Centrone, A.; Hatton, T.A.; Myerson, A.S. CrystEngComm 2011, 13, 1127-1131.

(19) Yang, X.; Sarma, B.; Myerson, A.S. Cryst. Growth Des. 2012, 12, 5521-5528.

(20) Meléndez, P.A.; Kane, K.M.; Ashvar, C.S.; Albrecht, M.; Smith, P.A. J. Pharm. Soc. $2008,97,2619-2636$. 
(21) Schroedl, N.; Brenn, G.; Zimmer, A.; Voura, C.; Eitzinger, B.; Gruber, M.M.; Strohmeier, D.; Bauer, W.; Khinast, J.G. Pharm. Tech. Eur. 2011, 23, 32-36.

(22) Sanandaji, N.; Oko, A.; Haviland, D.B.; Tholén, E.A.; Hedenqvist, M.S.; Gedde, U.W. Eur. Poly. J. 2013, 49, 1, 203-208.

(23) Sandler, N.; Määttänen, A.; Ihalainen, P.; Kronberg, L.; Meierjohann, A.; Viitala, T.; Peltonen, J. J. Pharm. Sci. 2011. 100, 8, 3386-3395

(24) Genina, N.; Fors, D.; Palo, M.; Peltonen, J.; Sandler, N. Int. J. Pharm. 2013, 453, 2, 488-497.

(25) Lee, A.Y.; Lee, I.S.; Myerson, A.S. Chem. Eng. Tech. 2006, 29, 2, 281-285

(26) Shen, X.; Ho, C.-M.; Wong, T.-S. J. Phys. Chem. B 2010, 114, 16, 5269-5274.

(27) Deegan, R.D.; Bakajin, O.; Dupont, T.F.; Huber, G.; Nagel, S.R.; Witten, T.A. Nature 1997, 389, 6653, 827-829.

(28) Seyedhosseini, E.; Ivanov, M.; Bystrov, V.; Bdikin, I.; Zelenovskiy, P.; Shur, V.Y.; Kudryavtsev, A.; Mishina, E.D; Sigov, A.S.; Kholkin, A.L. Cryst. Growth Des. $2014,14,6,2831-2837$

(29) Lee, I.; Lee, A.; Myerson, A. Pharm. Res. 2008, 25, 4, 960-968

(30) Trauffer, D.I.; Maassel, A.K.; Synder, R.C. Cryst. Growth Des. 2016, 16, $1917-$ 1922 


\section{TOC text:}

Inkjet printing technology is used to print picolitre droplets of aqueous glycine solution onto various substrates. From these droplets the highly metastable $\beta$ form was isolated. This is in contrast to conventional methods where the kinetically stable $\alpha$ form is usually seen. Analysis of crystal growth in droplets of increasing volume suggests that solvent-mediated phase conversion from $\beta$ to $\alpha$ is the predominant mechanism, but that rapid evaporation and special confinement in $\mathrm{pL}$ droplets traps the metastable form before phase conversion can occur.

\section{TOC image:}
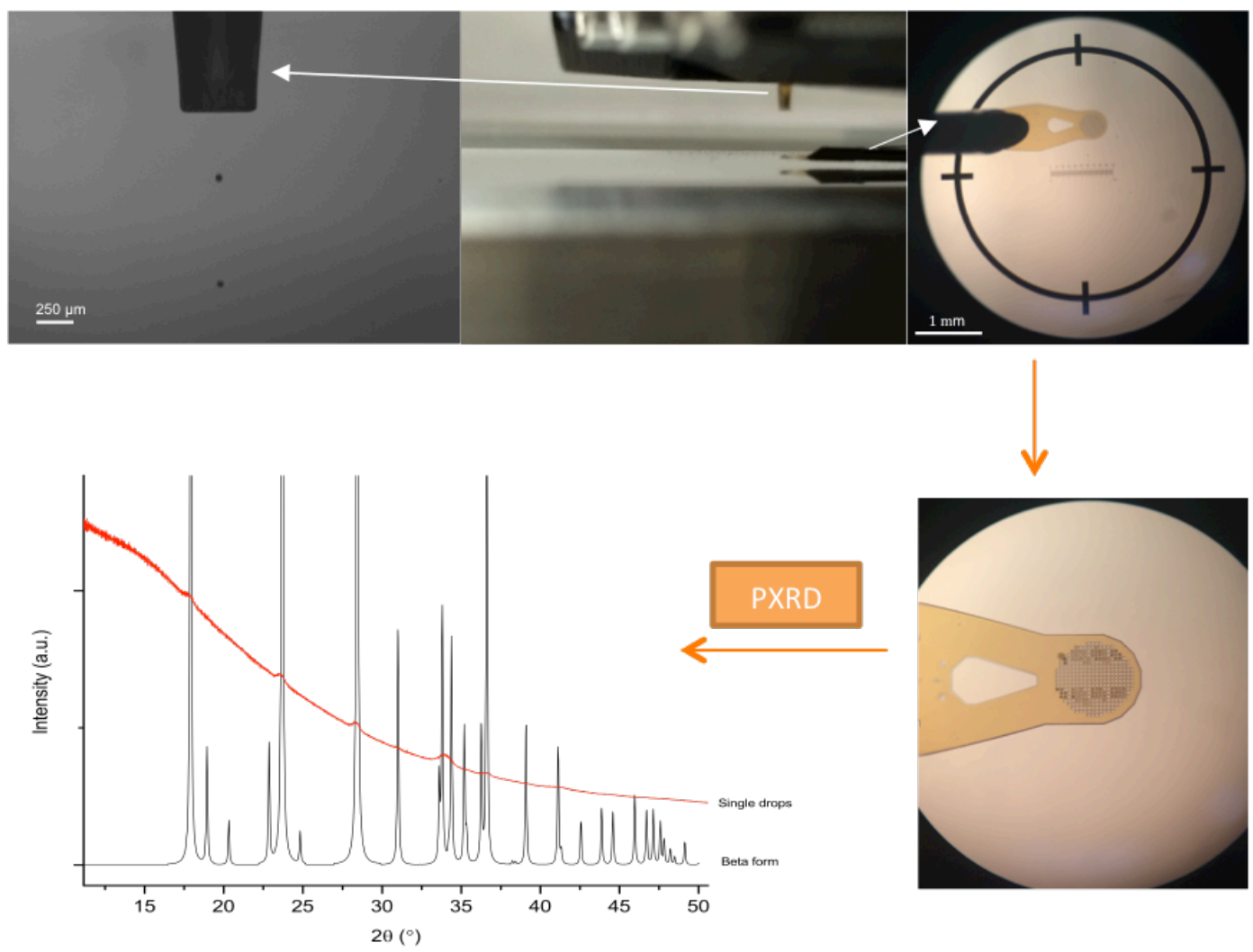